\title{
Understanding the surface oxide evolution of T91 ferritic-martensitic steel in supercritical water through advanced characterization
}

\author{
Kai Chen ${ }^{\text {a }}$, Lefu Zhang ${ }^{\text {a }}$, Zhao Shen ${ }^{\text {a,b,* }}$ \\ ${ }^{a}$ School of Nuclear Science and Engineering, Shanghai Jiao Tong University, 800 Dongchuan Road, Shanghai \\ 200240, China \\ ${ }^{\mathrm{b}}$ Department of Materials, University of Oxford, Parks Road, OX1 3PH Oxford, UK \\ Corresponding author: zhao.shen@materials.ox.ac.uk
}

\begin{abstract}
The surface oxide scale formed on T91 steel after exposure to deaerated supercritical water (SCW) at $600{ }^{\circ} \mathrm{C}$ for $100-1500 \mathrm{~h}$ are characterized in detail to reveal the oxide evolution over time. A triplex structure with outer, inner and internal oxide layers has been confirmed. The thickness of each oxide layer increases with the exposure time following the power law kinetics. The different oxide phases in each oxide layer are the results of the decreasing partial pressure of oxygen inwards the depth of oxide scale. The inner and internal oxide layers are not uniform in $\mathrm{Fe}$ and $\mathrm{Cr}$ contents. The internal oxide layer consists of $\mathrm{Cr}$-rich oxide precipitates surrounded by metal matrix in the grain interior, which could be explained by the internal oxidation mechanism. After a further longtime exposure, a continuous thin $\mathrm{Cr}$-rich spinel oxide layer is formed at the internal oxide layer-metal matrix interface, which is the result of transition from internal to external oxidation when the outward diffusion of $\mathrm{Cr}$ exceeds the inward diffusion of oxygen. The inner oxide layer consists of Cr-rich spinel oxide precipitates surrounded by Fe-rich spinel oxide. The formation of the inner oxide layer is the result of further oxidation of the internal oxide layer where the metal matrix in the grain interior is oxidized into Fe-rich spinel.
\end{abstract}

Key words: Ferritic-martensitic steel; Corrosion; Oxide evolution; TEM; TKD

\section{Introduction}

The supercritical water (SCW) cooled reactor has been considered as one of the most promising Generation IV nuclear reactors due to its high thermal efficiency and simplified design [1,2]. The outlet temperature in the designed SCW reactors is in the range of $500{ }^{\circ} \mathrm{C}$ to $600{ }^{\circ} \mathrm{C}$ [2-4], and one of the largest challenges for commercial use is the long-term performance of the cladding and structural materials at such high temperature [5]. Ferritic martensitic (F-M) steels, such as T91, were selected as candidate fuel cladding and core structural materials in SCW reactors because of their high radiation resistance, good high-temperature strength and creep resistance, high thermal conductivity, and low susceptibility to stress corrosion cracking (SCC) [6-8]. Under SCW conditions, the resistance to environmental degradation of structural materials depends critically on the formation and long-term stability of protective surface oxide in contact with corrosive environments [9]. Regardless of the various advantages, the common issue of F-M steels is the severe oxidation at elevated temperatures [10]. Therefore, the corrosion process and related oxidation mechanisms under SCW condition must be fully understood in order to better evaluate and control the in-service behavior of F-M steels. 
The oxidation behavior of F-M steels at elevated temperatures has been widely studied, and the results obtained in $\mathrm{SCW}$ are very similar to that in high-temperature steam, supercritical $\mathrm{CO}_{2}$, and liquid lead-bismuth eutectic (LBE) [10-12]. The typical oxide shows a duplex structure consisting of a defective magnetite outer layer and a protective spinel inner layer $[13,14]$. The outer oxide layer has been well known as $\mathrm{Fe}_{3} \mathrm{O}_{4}$ and the inner layer consists of $(\mathrm{Fe}, \mathrm{Cr})_{3} \mathrm{O}_{4}$. Tracer studies have confirmed that the original metal surface corresponded to the outer-inner layer interface [15-17]. That means the outer and inner oxide layers develop simultaneously, and the outer layer grows by the outward diffusion of Fe cations, while the inner layer grows by the inward diffusion of oxygen [18-21].

In addition to the duplex oxide structure, an internal oxide layer beneath the inner oxide has been frequently observed with selective oxidation along the grain/lath boundaries and nanometric Cr-rich oxide precipitates in the grain interior [10,22-30]. The formation mechanism of the internal oxide layer is still unclear, and more efforts have been made to reveal the evolution of the internal oxide layer in recent years. To date, the selective grain/lath boundary oxidation is the results of preferential oxygen penetration along the grain/lath boundaries, where the $\mathrm{Cr}$ carbides were firstly oxidized to form Cr-rich oxides [24-26,28,31-33]. In comparison, there are debates on the formation of the nanometric Cr-rich oxide precipitates in the grain interior. Bischoff et al. [33] attributed the formation of nanometric $\mathrm{Cr}$-rich oxide precipitates to the prior oxidation of $\mathrm{Cr}$ when the oxygen diffused inside the grains because of the negligible oxygen solubility in iron and high oxygen affinity of Cr. While Ye [10] proposed "internal oxidation" to explain the formation of nanometric Cr-rich oxide precipitates, where the presence of oxygen induces the short-range diffusion of $\mathrm{Cr}$ at the nanoscale to promote the formation of nano-clusters enriched in $\mathrm{Cr}$ [34,35]. The internal oxide layer locates at the metal-inner oxide layer interface and is the origin of the inner oxide layer, which makes it more critical in understanding the oxidation mechanisms. Therefore, further studies are needed to reveal the formation and evolution process of the internal oxide layer, especially the presence of the nanometric Cr-rich oxide precipitates inside the grains.

Except for the various explanation on the formation of the internal oxide layer, a continuous thin Cr-rich oxide layer is sometimes observed at the metal-internal oxide layer interface $[26,28,33]$, which has not received enough attention. Bischoff [33] observed a thin $\mathrm{Cr}_{2} \mathrm{O}_{3}$ layer at the metal-oxide interface in $9 \mathrm{Cr}$ oxide dispersion strengthened (ODS) steel and HCM12A steel after 4 weeks exposure to $\mathrm{SCW}$ at 500 and $600{ }^{\circ} \mathrm{C}$, but this thin $\mathrm{Cr}_{2} \mathrm{O}_{3}$ layer did not show up after 2 weeks exposure in the 9Cr ODS steel. In comparison, Ye [10] observed a Cr-depletion zone instead of a Cr-rich oxide layer at the metal-oxide interface of T91 in LBE, and attributed it to the micron-scale diffusion of $\mathrm{Cr}$ from the matrix into the internal oxide layer. The occurrence of the thin Cr-rich oxide layer seems to depend on the environmental parameters, as well as exposure times. To date, the formation of this thin Cr-rich oxide layer at the oxidation front has not been studied either experimentally or theoretically. It is well known that Cr-rich oxide is more protective than Fe-rich oxide [33], and could play a key role in determining the oxidation process of F-M steels. Thus, more works are needed to study the initiation and evolution mechanisms of the Cr-rich oxide layer at the metal-internal oxide layer interface.

To date, various oxidation mechanisms and models have been proposed to interpret the formation and evolution of the surface oxide for F-M steels in different environments. The "available space model", which was firstly proposed by Bruckman and Romanski in 1965 [18], has been recognized as the most successful one. This model considers the outer-inner oxide layer interface as the original metal surface. The outer and inner oxide layers grow simultaneously due to the outward diffusion of $\mathrm{Fe}$ and inward diffusion of oxygen. The outward diffusion of $\mathrm{Fe}$ is considered as the rate-limiting factor for the overall oxidation process, which leaves behind vacancies and pores at the metal-oxide interface. These vacancies and pores would finally condense into voids, also called "available space", and act as nano/micro-channels to permit the inward diffusion of oxidants. Although the widely accepted "available space model" [18-21] well predicts the oxidation kinetics, and gives rational explanations for the 
observed oxide structures in the macro-scale, the in-depth micro-scale or nano-scale oxide evolution, especially the oxide transformation between different oxide layers, is still unclear and under debates. To clarify the oxidation mechanism in SCW, the surface oxides of T91 with different exposure times in $600{ }^{\circ} \mathrm{C}$ deaerated SCW were carefully characterized by various advanced characterization techniques in this work.

\section{Experimental}

The material used in this study is T91 steel with the chemical composition of $0.092 \mathrm{C}, 0.45 \mathrm{Mn}, 0.012 \mathrm{P}, 0.002$ $\mathrm{S}, 0.25 \mathrm{Si}, 0.23 \mathrm{Ni}, 8.93 \mathrm{Cr}, 0.82 \mathrm{Mo}, 0.18 \mathrm{Cu}, 0.21 \mathrm{~V}, 0.048 \mathrm{~N}$ (wt. \%). Rectangular specimens $\left(15 \times 10 \times 2 \mathrm{~mm}^{3}\right)$ were machined from the as-received plate material, followed by surface polishing up to $1.0 \mu \mathrm{m}$ diamond suspension solution. The dimension and weight of each specimen were measured prior to the SCW exposure.

Corrosion test was carried out in an SCW environment at $600{ }^{\circ} \mathrm{C}$ with the pressure of $25 \mathrm{MPa}$. An argon deaerated pure water was maintained by a circulating water loop at a water flow rate of $2-3 \mathrm{~L} / \mathrm{h}$. The continuously monitored conductivity and dissolved oxygen at the outlet of the water loop showed values below $0.2 \mu \mathrm{S} / \mathrm{cm}$ and $10 \mathrm{ppb}$, respectively. More details about the testing system can be found in [36-41]. The corrosion test was interrupted after $100 \mathrm{~h}$ and $600 \mathrm{~h}$ to remove several specimens from the autoclave, and the whole test was terminated after $1500 \mathrm{~h}$ exposure.

After the test, the weights of the specimens with different exposure times were measured, and the surface oxide was carefully characterized. Specifically, the weight was measured by a Mettler Toledo AL104 Analytical Balance with the resolution of $0.1 \mathrm{mg}$. The morphology, element distribution, and phases of the cross-sectional surface oxide were characterized by a Zeiss Field Emission Gun (FEG) Scanning Electron Microscope (SEM) equipped with Oxford Instruments X-max 150 Energy Dispersive X-ray (EDX) detector and NordlysMax 3 Electron Backscattered Diffraction (EBSD) detector systems. Transmission Electron Microscope (TEM) lift-outs were prepared and further thinned by a dual beam Zeiss NVision 40 Focused Ion Beam (FIB). High-resolution Transmission Kikuchi Diffraction (TKD) and Analytical TEM (ATEM) analyses on the TEM foils were conducted by a Zeiss Merlin FEGSEM equipped with an Optimus TKD detector and an aberration-corrected JEOL ARM200F equipped with a Quantum Gatan image filter spectrometer, respectively.

\section{Results}

\subsection{Microscale analysis: EDX and EBSD characterization}

After exposure to $600{ }^{\circ} \mathrm{C} \mathrm{SCW}$ for $1500 \mathrm{~h}$, the sample developed a triplex surface oxide scale (Fig. 1): a continuous outer oxide layer with high density defects (voids and cracks), underneath which is a relatively dense inner oxide layer followed by an internal oxide layer (also referred to as diffusion layer $[26,33,36]$ or transition layer $[2,28]$ in literature) closest to the metal matrix. The SEM-EDX results in Figs. 1c-e show that the outer oxide layer is made of Fe-rich oxide. The inner oxide layer is enriched in $\mathrm{Fe}$ and $\mathrm{Cr}$, which could be $\mathrm{Fe}-\mathrm{Cr}$ spinel. Compared with the inner oxide layer, the internal oxide layer contains much less $\mathrm{O}$ and more Fe. The $\mathrm{O}$ distribution (Fig. 1c) is not uniform in the internal oxide layer with some precipitates enriched in O. Similar triplex oxide structure has been observed in F-M steels after exposure to $\mathrm{SCW}$, supercritical $\mathrm{CO}_{2}$, liquid $\mathrm{LBE}$, and high-temperature water vapor [10-12], but the morphology and thickness of the oxide layers varied from study to study, depending on the testing parameters and exposure times. 

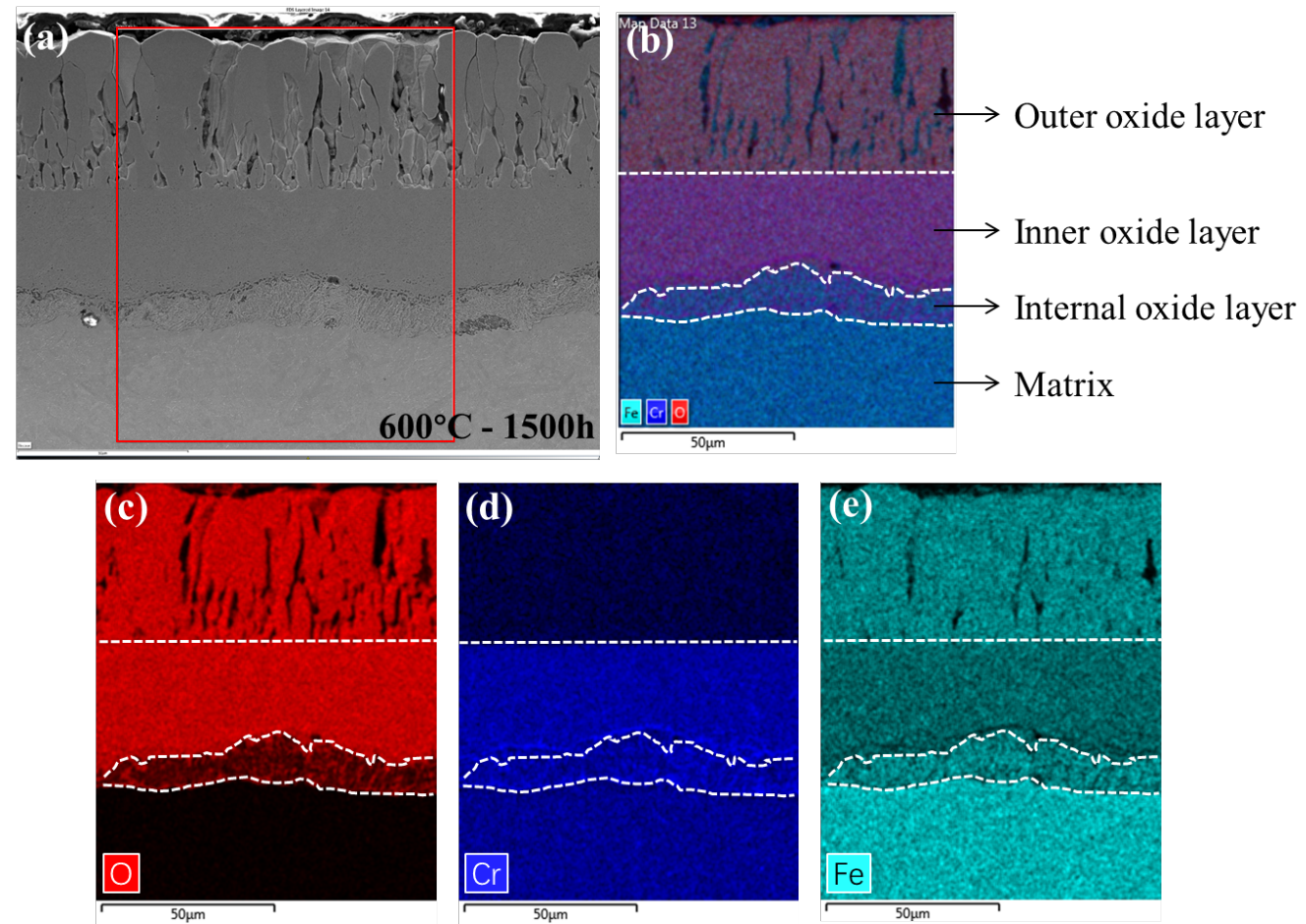

Fig. 1. Cross-sectional SEM-EDX elemental distribution maps of the surface oxide film on T91 exposed to SCW for $1500 \mathrm{~h}$ at $600{ }^{\circ} \mathrm{C}$. (a) SEM image, (b) Fe, Cr, O overlapping image showing the triplex oxide structure, and (c-

e) $\mathrm{O}, \mathrm{Cr}$ and Fe elemental maps of the surface oxide.

Fig. 2 shows the SEM-EBSD results of the cross-sectional oxide scale on T91 after exposure to SCW for 1500 $\mathrm{h}$ at $600{ }^{\circ} \mathrm{C}$. The pattern quality and inverse pole figure (IPF) images clearly distinguish the triplex oxide with face centered cubic (FCC) structure from the metal matrix with body centered cubic (BCC) structure. The EBSD images also reveal the grain morphology in each oxide layer. The outer oxide layer shows large columnar grains parallel to the growth direction of the surface oxide scale. The grain size is smaller near the inner-outer layer interface, while it is larger and more uniform near the oxide-water interface. The outer oxide layer also shows a high density of voids and large cracks (see Figs. 1a and 2a), which agrees well with the observed surface cracks as marked in Supplementary Fig. 1.

The inner and internal oxide layers show much smaller grain size than the outer oxide layer and matrix. The inner oxide layer is believed to consist of Fe-Cr spinel, while there is debate on the structure of the internal oxide layer. Several studies showed that oxygen diffused along the grain/lath boundaries and mainly oxidized the carbides, and the grain interior remained as matrix in the internal oxide layer [23,26]. Additionally, some other work [10,26,33] also revealed nanometric $\mathrm{Cr}$-rich oxide precipitates inside the grain interior in the internal oxide layer. The structure of the internal oxide layer is more complex than the inner and outer oxide layers, thus further high-resolution TEM characterization of the internal oxide layer were conducted and will be given below to reveal the detailed oxide structures.

The cross-sectional SEM-EDX and EBSD results of the surface oxide after exposure in SCW for $100 \mathrm{~h}$ and $600 \mathrm{~h}$ are shown in Supplementary Figs. 2 and 3. Regardless of the exposure time, all the oxide films show similar triplex structure, but with different oxide thickness. Each oxide layer grows thicker simultaneously with the longer exposure time. Despite the large defects in the outer oxide layer, considerable porosity in the inner oxide has also been revealed, which decreases with increasing exposure time. This densification of the inner oxide layer with 
increasing exposure time could be explained by the "available space model" [18-21]. At the beginning of the oxidation process, the outward Fe diffusion leaves abundant vacancies and voids behind, also called as "available space". With increasing exposure time, the oxidant diffuses inward to form new oxide in this "available space", thus decreases the porosity of the inner oxide layer.
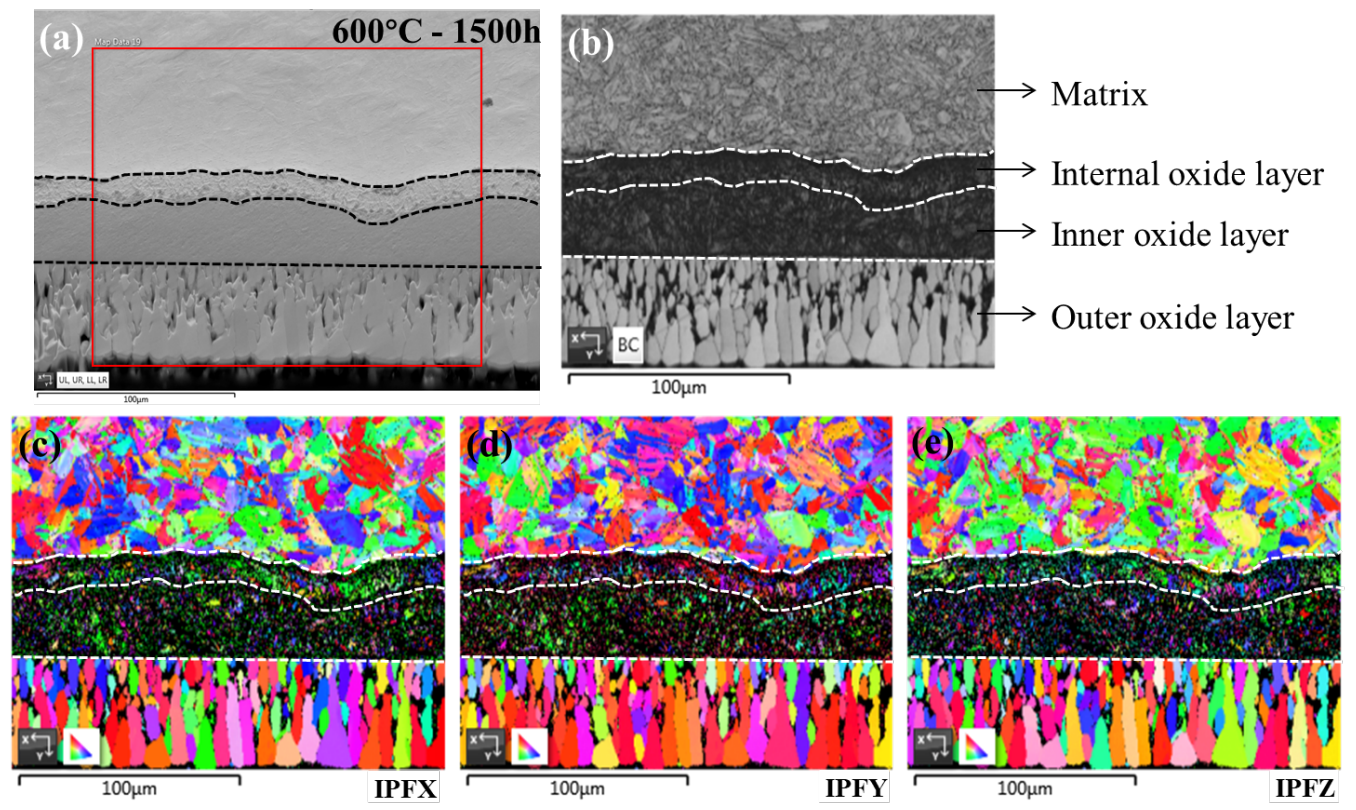

Fig. 2. Cross-sectional SEM-EBSD images of the surface oxide film on T91 exposed to SCW for $1500 \mathrm{~h}$ at 600 ${ }^{\circ} \mathrm{C}$. (a) SEM image, (b) pattern quality image, and (c-e) IPF images of the surface oxide.

\subsection{Surface oxide scale after different exposure times}

Figs. 3a-c compares the SEM-EDX line-scan results across the surface oxide with different exposure times. The thicknesses of different oxide layers are summarized in Table 1. The composition profiles show that the oxygen content remains nearly constant in the outer and inner oxide layers. The outer oxide layer is predominantly $\mathrm{Fe}$ oxide with an $\mathrm{O} / \mathrm{Fe}$ ratio of $\sim 1.31$, corresponding to the composition of magnetite $\mathrm{Fe}_{3} \mathrm{O}_{4}$. The inner oxide layer shows a similar oxygen-metal $(\mathrm{O} / \mathrm{M})$ ratio, confirming the oxide structure of $\mathrm{Fe}-\mathrm{Cr}$ spinel $(\mathrm{Fe}, \mathrm{Cr})_{3} \mathrm{O}_{4}$. The internal oxide layer shows gradients of $\mathrm{Fe}$ and $\mathrm{O}$ with high undulations. The relative $\mathrm{Cr}$ contents in inner and internal oxide layers are close to the bulk metal value, which means that the diffusion of $\mathrm{Cr}$ across the oxide is negligible. Several peaks in $\mathrm{Cr}$ content are observed in the oxide and matrix, and it is supposed to come from the Cr-rich carbides along the grain/lath boundaries.

It has been widely accepted that the outer-inner oxide interface corresponds to the original metal surface, and the outward diffusion of $\mathrm{Fe}$ is oxidized to form the outer oxide layer [15-21]. The outward diffusion of $\mathrm{Fe}$ is believed to originate from the internal oxide layer rather than the inner oxide layer or matrix, since the concentration gradient of Fe is only observed in the internal oxide layer. According to the "available space model", when Fe diffuses out and leaves abundant vacancies behind, the oxidant diffuses inward to the metal-oxide interface to form new oxide in this "available space". It suggests that the growth rates of the outer and inner oxide are the same, which agrees well with the relatively constant thickness ratio of the inner to outer oxide layers (Table 1). The slightly lower ratio for $1500 \mathrm{~h}(0.61)$ might be related to the denser inner oxide with a longer exposure time.

Fig. $3 \mathrm{~d}$ shows the weight change and oxide thickness change as a function of exposure time. The growth exponent of weight gain is $\sim 0.4$, indicating that the oxidation follows a growth behavior in between parabolic and 
cubic growth kinetics models [42]. Although the thickness of each oxide layer is different, similar oxide growth behavior is identified with the growth exponent of 0.35-0.48. This further confirms that the oxidation in the three oxide layers eecurs simultaneusly-keeps increasing with increasing exposure time, contributing to the overall growth of the surface oxide. This is also evident in the proportional correlation between the weight gain and the thickness of each oxide layer as shown in Fig. 3e.

The widely accepted oxidation model of F-M steels is the "available space model" [18-21], which believes that the outward diffusion of $\mathrm{Fe}$ and inward diffusion of $\mathrm{O}$ are the evolution process of oxide growth. The relatively constant $\mathrm{Fe}$ and $\mathrm{O}$ contents indicate that the diffusion of $\mathrm{Fe}$ and $\mathrm{O}$ is not limited in the inner and outer oxide layers, while the gradients of $\mathrm{Fe}$ and $\mathrm{O}$ in the internal oxide layer show that the internal oxide layer is crucial for the diffusion of $\mathrm{Fe}$ and $\mathrm{O}$. That means the internal oxide layer should be the regulation of the overall oxide growth during high-temperature oxidation process for T91. Thus, detailed characterization of the internal oxide layer is carried out in the following sections.
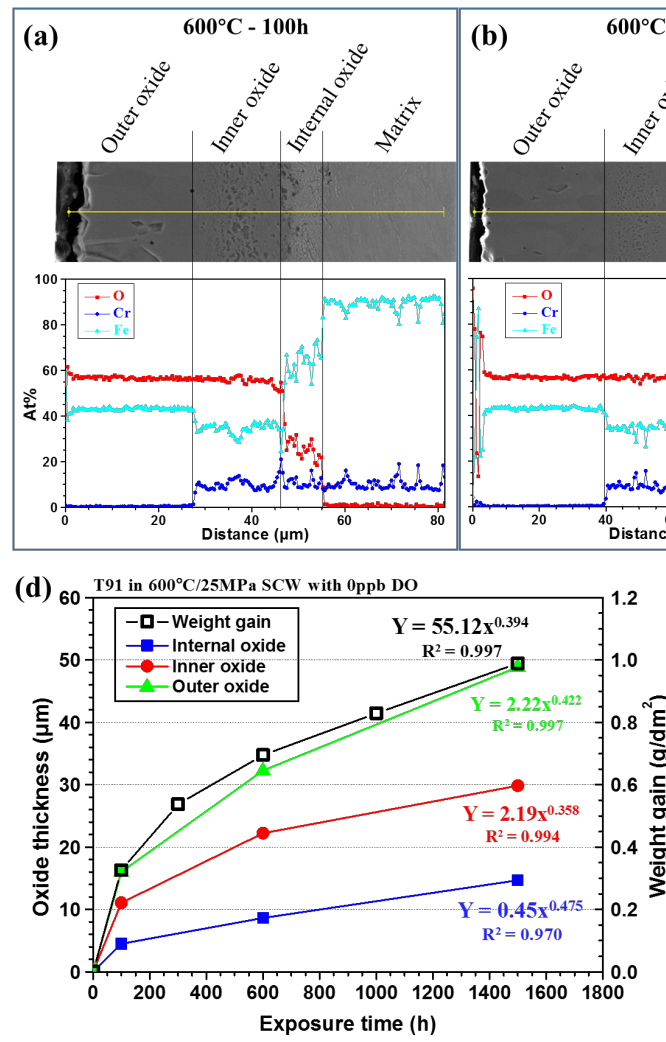
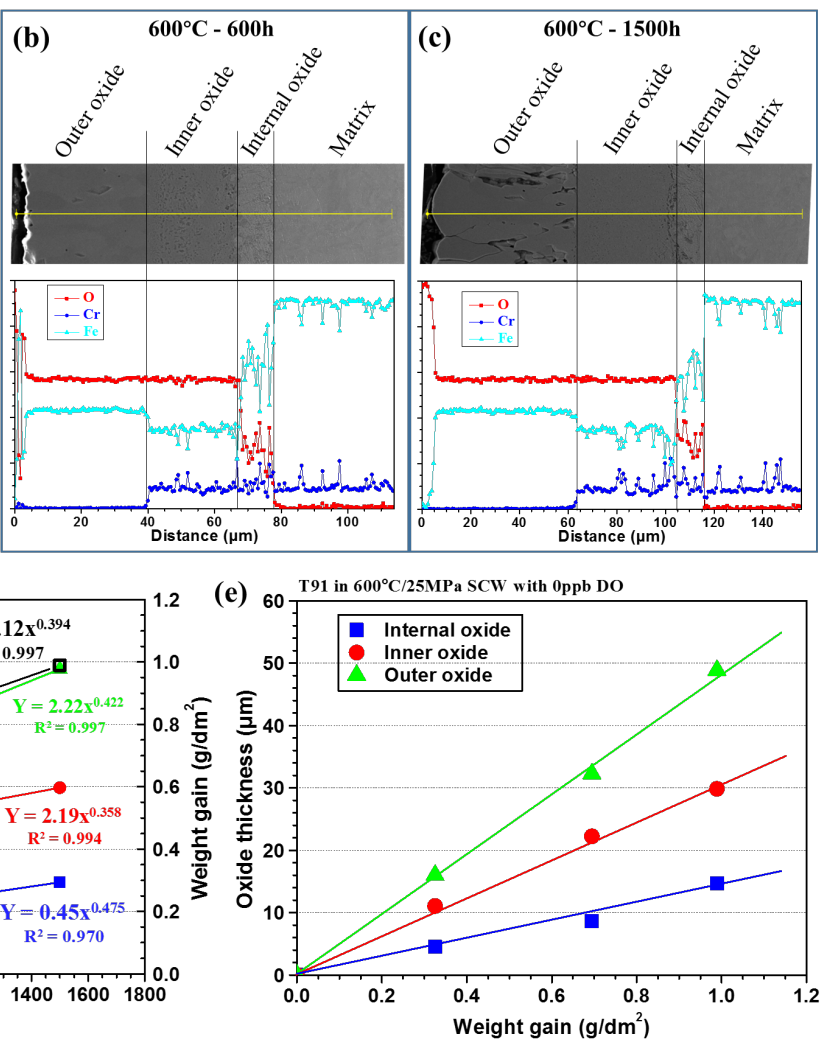

Fig. 3. Cross-sectional SEM-EDX line scanning results of the surface oxide film on T91 exposed to SCW for (a) $100 \mathrm{~h}$, (b) $600 \mathrm{~h}$ and (c) $1500 \mathrm{~h}$ at $600{ }^{\circ} \mathrm{C}$; (d) the oxide thickness and weight gain as a function of exposure time; (e) the oxide thickness as a function of weight gain in each oxide layer.

Table 1 Summary of the oxide features of T91 with different exposure times

\begin{tabular}{cccccccc}
\hline \multirow{2}{*}{ Exposure time } & \multicolumn{4}{c}{ Oxide thickness $(\mu \mathrm{m})$} & \multicolumn{2}{c}{$\mathrm{O} / \mathrm{M}$ ratio ${ }^{*}$} & \multirow{2}{*}{ Inner/Outer thickness } \\
\cline { 2 - 6 } & Outer & Inner & Internal & Total & Outer & Inner & \\
\hline \multirow{2}{*}{$100 \mathrm{~h}$} & 16.0 & 11.1 & 4.5 & 31.6 & 1.31 & 1.26 & 0.69 \\
\hline
\end{tabular}




\begin{tabular}{rrrrrrrl}
\hline $600 \mathrm{~h}$ & 32.3 & 22.2 & 8.6 & 63.1 & 1.31 & 1.29 & 0.69 \\
\hline $1500 \mathrm{~h}$ & 48.8 & 29.8 & 14.7 & 93.3 & 1.32 & 1.31 & 0.61 \\
\hline
\end{tabular}

* Atom ratio, $\mathrm{M}=\mathrm{Fe}+\mathrm{Cr}$

\subsection{Nanoscale analysis: ATEM and TKD characterization}

Although the internal oxide layer has been observed by many studies [10,22-30], its effect on the oxidation process has not been well understood. To reveal the microstructure evolution of the internal oxide layer during the exposure, two TEM foils were lifted out at the inner-internal oxide layers and internal oxide layer-matrix interfaces after exposure for $1500 \mathrm{~h}$. The locations of the TEM foils are indicated in Fig. 4. The characterization results obtained from these two foils are believed to help to understand the transformation of matrix to internal oxide layer and internal to inner oxide layers, thus revealing the oxidation process.

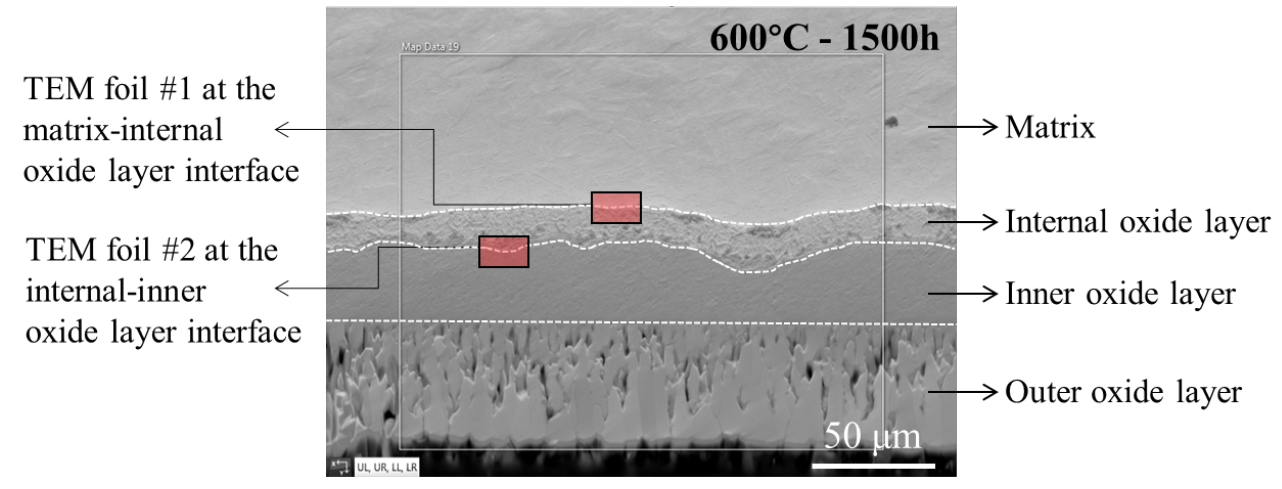

Fig. 4. The locations of the TEM foils in the oxide of T91 after exposure in SCW at $600{ }^{\circ} \mathrm{C}$ for $1500 \mathrm{~h}$.

Fig. 5 shows the TEM high angle annular dark field (HAADF) images at the matrix-internal oxide layer interface in TEM foil \#1. It is very clear that the internal oxide layer has not been fully oxidized and nano-metric to sub-micron oxide precipitates are observed, which agrees well with the non-uniform O distribution in the SEMEDX results (Fig. 1c). Large oxide precipitates seem to locate along the grain/lath boundaries, while small oxide precipitates tend to form in the grain interior. This oxide precipitation morphology in the internal oxide layer has also been observed in $\mathrm{HCM} 12 \mathrm{~A}$ steel exposed to $600{ }^{\circ} \mathrm{C} \mathrm{SCW}$ [26], and in T91 steel after exposure in $550{ }^{\circ} \mathrm{C}$ liquid LBE [10]. Moreover, a continuous thin oxide layer is identified in front of the internal oxide layer with the thickness of about a half micrometer. This layer has also been reported in $[26,28,33]$, but it did not receive enough description and discussion. Further electron energy loss spectroscopy (EELS) analysis in Fig. 6 confirms that the oxide precipitates in the internal oxide layer and the continuous thin oxide layer are enriched with $\mathrm{Cr}$, which are believed to be Cr-rich spinel oxide. The rest part in the internal oxide layer is pure matrix without being oxidized. To confirm this hypothesis, high-resolution TKD technique was utilized to reveal the grain and phase distributions at the metaloxide interface, and the results are shown in Fig. 7. The non-oxidized region in the internal oxide layer is identified to have a BCC structure, which is the same with the unaffected metal matrix. The oxide precipitates in the internal oxide layer and the continuous thin Cr-rich oxide layer have an FCC spinel structure. The IPF images show that the oxide is randomly oriented without specific orientation. In summary, the internal oxide layer is confirmed to consist of a mixture of $\mathrm{Cr}$-rich spinel oxide precipitates and metal matrix. Both the continuous thin $\mathrm{Cr}$-rich oxide layer at the internal oxide layer front and $\mathrm{Cr}$-rich oxide precipitates are revealed to have an $\mathrm{FCC} \mathrm{Fe}-\mathrm{Cr}$ spinel structure, instead of hexagonal close packed structure $\left(\mathrm{Cr}_{2} \mathrm{O}_{3}\right)$.

Similar morphology of the internal oxide layer after $100 \mathrm{~h}$ exposure is also observed by HAADF (see 
Supplementary Fig. 4). However, the continuous Cr-rich oxide layer beneath the internal oxide layer after $1500 \mathrm{~h}$ exposure in Fig. 5 is very unique, and did not show up in the sample with $100 \mathrm{~h}$ exposure (see Supplementary Fig. 4a). It seems that the exposure time has a critical effect on the formation of this continuous Cr-rich oxide layer, which will be discussed later.
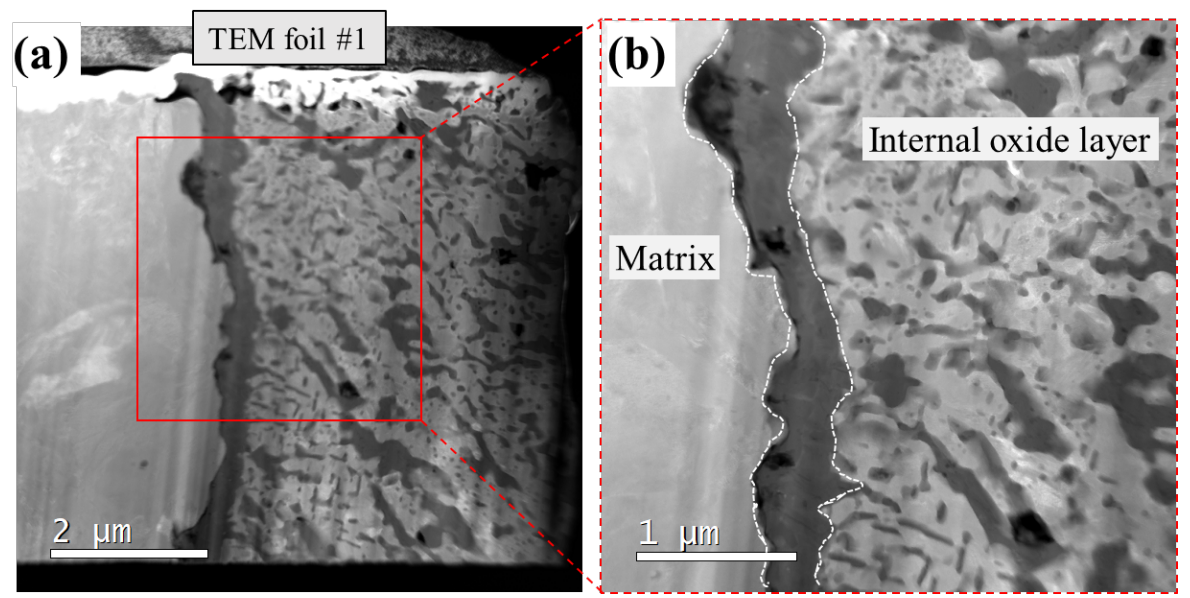

Fig. 5 (a) TEM foil \#1 and (b) TEM HAADF image at the matrix-internal oxide layer interface of T91 after exposure in SCW at $600{ }^{\circ} \mathrm{C}$ for $1500 \mathrm{~h}$.
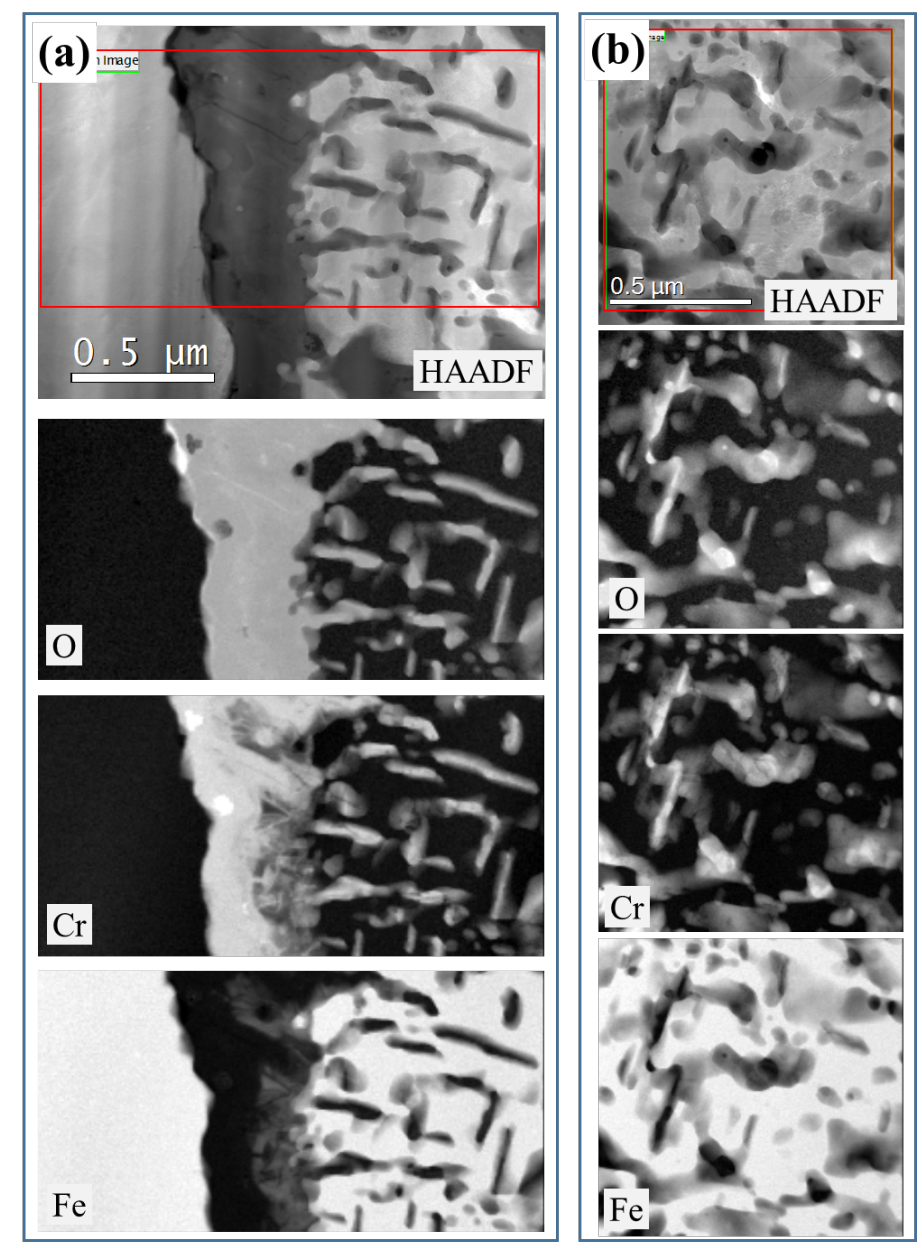

Fig. 6 EELS analysis results (a) at the matrix-internal oxide layer interface, (b) in the internal oxide layer of T91 after exposure in SCW at $600{ }^{\circ} \mathrm{C}$ for $1500 \mathrm{~h}$. 

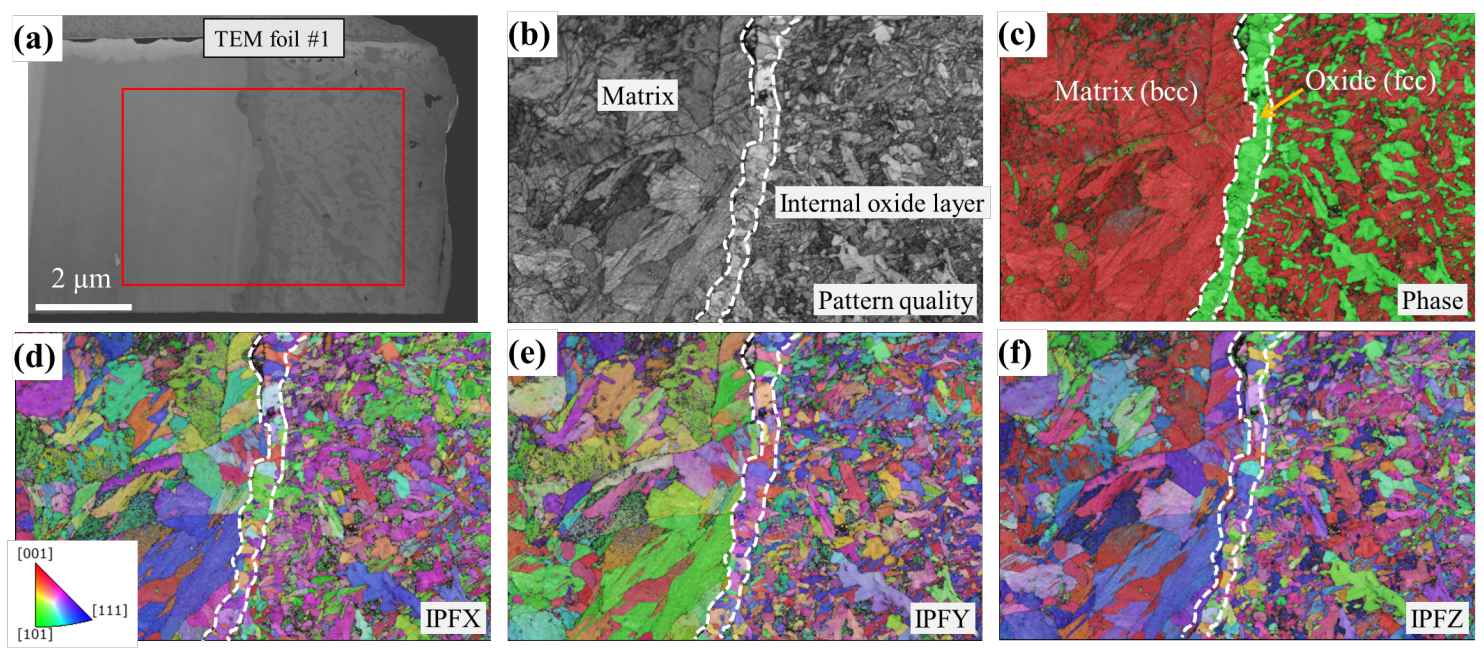

Fig. 7 TKD analysis results at the matrix-internal oxide layer interface of T91 after exposure in SCW at $600{ }^{\circ} \mathrm{C}$ for 1500 h. (a) SEM image, (b) pattern quality map, (c) phase map and (d-f) IPF maps.

Fig. 8 shows the HAADF images at the internal-inner oxide layers interface of TEM foil $\# 2$. There is a high density of defects (voids and micro-cracks) at the interface between the inner and internal oxide layers as shown in Fig. 8b. These defects are also observed for all the specimens with the exposure time of $100 \mathrm{~h}, 600 \mathrm{~h}$ and $1500 \mathrm{~h}$ as shown in the SEM images, thus they were not caused by the milling or thinning during the preparation of TEM samples by FIB. Distinct defects have also been revealed at the inner-internal oxide layer interface on P92 exposed in SCW for $1000 \mathrm{~h}$ at $550^{\circ} \mathrm{C}$ and for $600 \mathrm{~h}$ and $1000 \mathrm{~h}$ at $600{ }^{\circ} \mathrm{C}$ [22]. The authors believed that the formation of these defects is related to the internal stress within the oxide, which originates from the oxide growth during the test and the thermal stress during the process of specimen cooling. Also, a high density of defects in the inner oxide layer has also been revealed after $100 \mathrm{~h}$ exposure as shown in Fig. 3a and Supplementary Fig. 2a. It seems that these defects originated at the inner-internal interface due to outward Fe diffusion, and transformed into defective inner oxide layer. With increasing exposure time, the density of defects in the inner layer decreases (Figs. 3a-c) because new Fe-rich oxides continue to form inside these defects.

Fig. 8a shows the internal oxide layer morphology adjacent to the internal-inner oxide layers interface. Oxidation along the grain/lath boundaries as well as oxide precipitates in the grain interior are observed. The grain/lath boundary oxidation is more pronounced than that near the metal-internal oxide layer interface (Fig. 5b). The grain/lath boundary oxidation in the internal oxide layer has also been revealed in previous research [10,22-30], which is believed to be the result of enhanced oxidant diffusion along the grain/lath boundaries. Comparing with the partially oxidized internal oxide layer, the inner oxide layer is $100 \%$ oxidized, as shown in Fig. 8c. However, the oxide in the inner oxide layer is not very uniform with different contrast. There seems to be more than one type of oxide in the inner oxide layer. To confirm this, EELS and TKD analysis were carried out at the internal-inner oxide layer interface. 

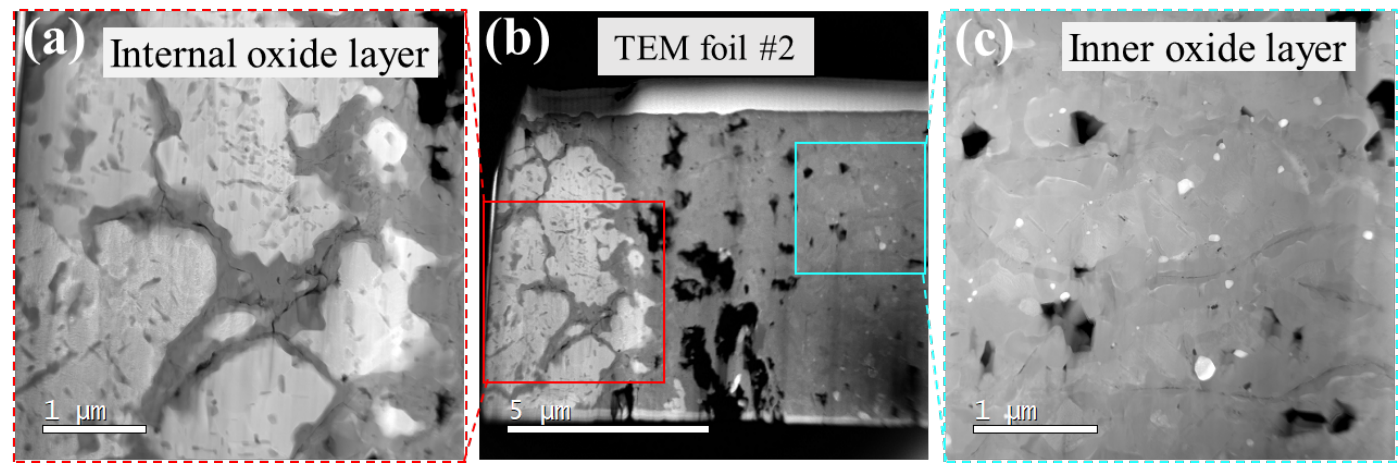

Fig. 8 TEM HAADF images at the internal-inner oxide layer interface of T91 after exposure in SCW at $600{ }^{\circ} \mathrm{C}$ for $1500 \mathrm{~h}$.

Fig. 9 shows the EELS images around the internal-inner oxide layers interface. Part of the region in the internal oxide layer is enriched with $\mathrm{Fe}$, and remains un-oxidized as matrix (Fig. 9a). Although the inner oxide layer has been fully oxidized as indicated by the $\mathrm{O}$ distribution in Fig. 9b, Cr-rich oxide precipitates are still observed in this layer. The rest part in the inner oxide layer is enriched in Fe and nearly exhausted in Cr. Consequently, the inner oxide layer consists of Cr-rich oxide precipitates surrounded by Fe-rich oxide. Since the morphology and distribution of the Cr-rich oxide precipitates in the inner oxide layer is very similar to that in the internal oxide layer, it is sensible to postulate that the inner oxide layer is developed from the internal oxide layer when more $\mathrm{O}$ diffuses into it and further oxidize the matrix into Fe-rich oxide.

Fig. 10 shows the TKD results at the internal-inner oxide layer interface. The non-oxidized region in the internal oxide layer is identified as BCC metal matrix, while all the other parts in the inner and internal oxide layers shows an FCC spinel structure (Fig. 10c). In the internal oxide layer, the original grain boundaries are preferentially oxidized and decorated by the continuous oxide lathes. Small oxide precipitates are observed within the grains. Although the inner oxide layer consists of two kinds of oxide enriched in $\mathrm{Fe}$ or $\mathrm{Cr}$ (Fig. 9b), both the $\mathrm{Cr}$-rich and Fe-rich oxides show an FCC spinel structure of $(\mathrm{Fe}, \mathrm{Cr})_{3} \mathrm{O}_{4}$ (Fig. 10c). 


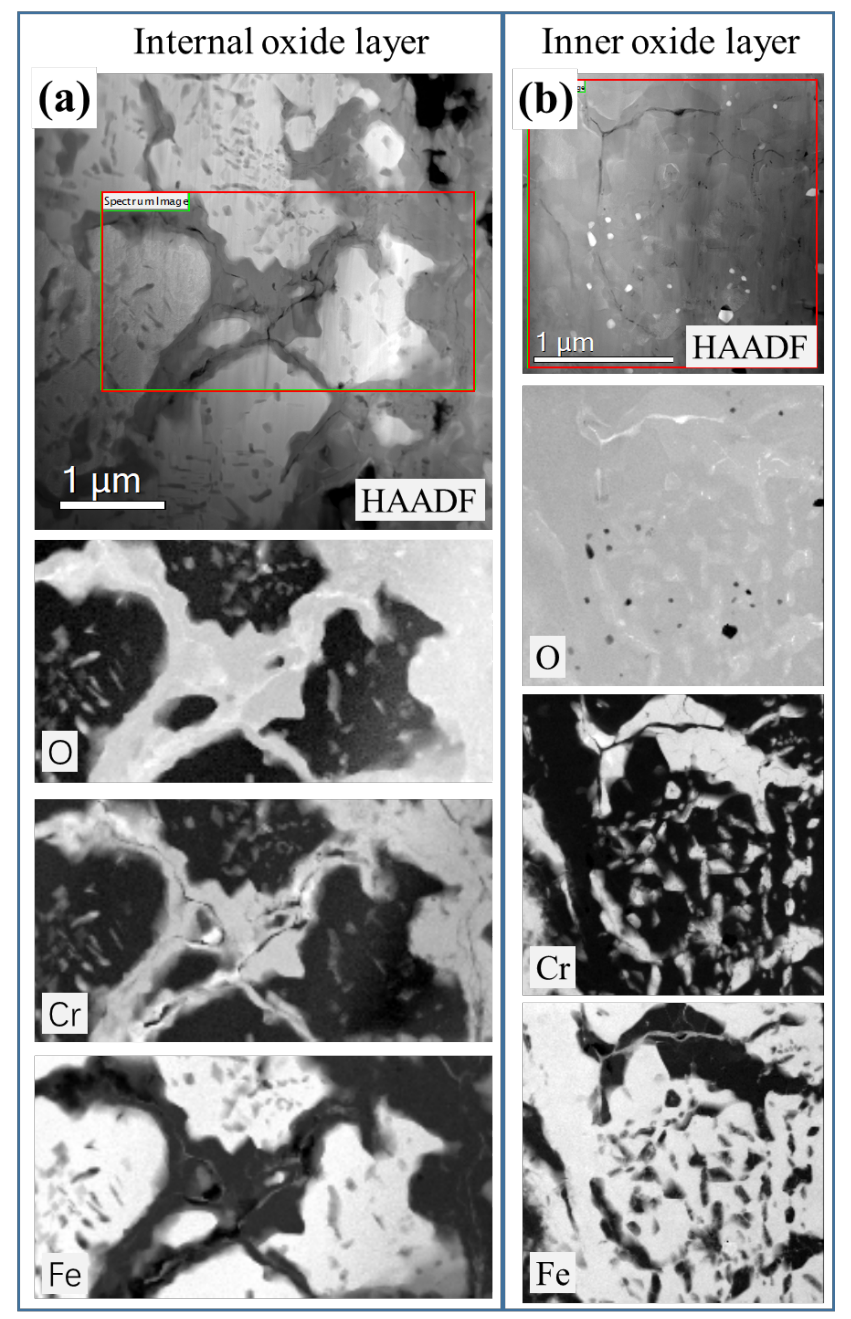

Fig. 9 EELS analysis results (a) in the internal oxide layer, (b) in the inner oxide layer at the internal-inner oxide layer interface of T91 after exposure in SCW at $600^{\circ} \mathrm{C}$ for $1500 \mathrm{~h}$.
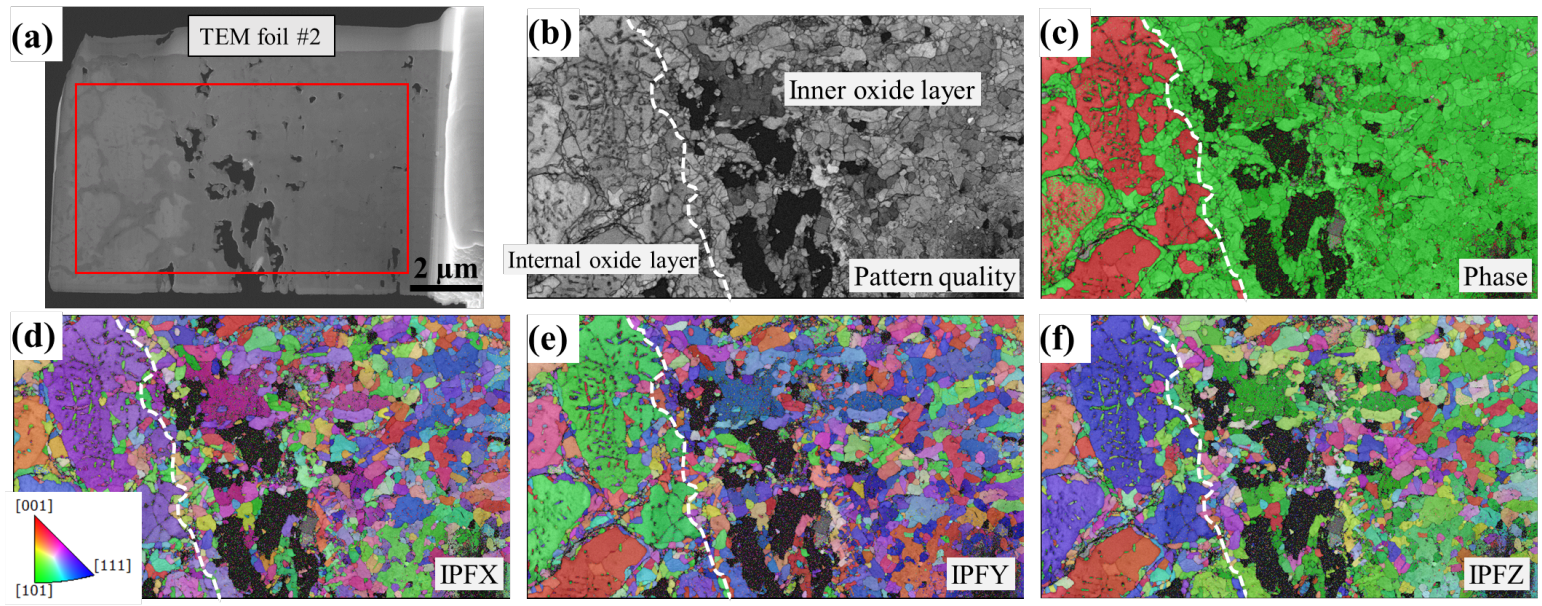

Fig. 10 TKD images at the internal-inner oxide layer interface of T91 after exposure in SCW at $600{ }^{\circ} \mathrm{C}$ for $1500 \mathrm{~h}$. (a) SEM image, (b) pattern quality map, (c) phase map and (d-f) IPF maps. 


\section{Discussion}

\subsection{The evolution of oxide over exposure time}

The oxide structure of T91 steel in $600{ }^{\circ} \mathrm{C} \mathrm{SCW}$ exhibits very limited microstructural variations with different exposure times, but mainly shows the increases in weight gain and oxide thickness. The weight gain as a function of time follows a power law with the time exponent of 0.394 (Fig. 3d), which deviates from the expected parabolic kinetics with the time exponent of 0.5 . Most of the literature data also show lower time exponents in the range of 0.29-0.45 [7], and this deviation from the theoretical parabolic law is believed to be caused by the inhomogeneous surface oxide structure [7,43-45]. Theoretically, the parabolic law is derived from the transport of either vacancies or interstitials of ions through a uniform oxide film [7]. However, the oxide film consists of defects, such as voids and cracks (Figs. 1 and 2), and the density of defects also changes with exposure time. These defects act as shortcircuit paths for diffusion of ions, thus increase the effective diffusivity and affect the time dependence of oxidation behavior.

In addition to the triplex oxide layers, a continuous thin Cr-rich oxide layer is observed just at the matrixinternal oxide layer interface after $1500 \mathrm{~h}$ exposure (Fig. 5), but it is not observed in the specimen with the exposure times of $100 \mathrm{~h}$ (Supplementary Fig. 4). The EELS and TKD results (Fig. 6 and Fig. 7) confirmed that this Cr-rich oxide layer has a FCC spinel structure $\left((\mathrm{Fe}, \mathrm{Cr})_{3} \mathrm{O}_{4}\right)$, and is enriched in $\mathrm{Cr}$ and depleted in Fe. The main difference between the oxide films with different exposure times is the oxide thickness, which could affect the inward diffusion of oxidant and outward diffusion of Fe. For the specimen with a longer exposure time (such as $1500 \mathrm{~h}$ ), the oxide film grew thicker to highly slow down the inward diffusion of oxidant, resulting in a very low corrosion potential at the metal-oxide interface. It is reported that $\mathrm{Cr}$ is more active than Fe to react with oxygen to form oxide [33]. Thus, mainly $\mathrm{Cr}$ and much less $\mathrm{Fe}$ was oxidized at such low corrosion potential to form the continuous $\mathrm{Cr}$-rich spinel oxide layer at the metal-oxide interface. In comparison, the oxide film with the exposure time of $100 \mathrm{~h}$ is about three times thinner, and the inward diffusion of oxidant creates a high corrosion potential at the metal-oxide interface that could oxidize both $\mathrm{Cr}$ and $\mathrm{Fe}$ to form the internal oxide layer. Further discussion on the formation of the internal oxide layer and the continuous $\mathrm{Cr}$-rich oxide layer at the metal-oxide interface will be given in the following sections.

\subsection{Dependence of oxide phases on the partial pressure of oxygen}

According to the SEM and TEM results, the surface oxide film formed on T91 steel after exposure in $600{ }^{\circ} \mathrm{C}$ SCW for $1500 \mathrm{~h}$ has a triplex structure as well as a thin continuous Cr-rich spinel oxide layer at the matrix-internal oxide layer interface. Different oxide layers show different oxide structures and morphologies. In contrast to the well-understood outer and inner oxide layers, the formation and evolution of the internal oxide layer, especially the continuous Cr-rich oxide layer has not been fully studied experimentally or theoretically.

At thermodynamic equilibrium, the formation of oxide phases depends on the partial pressure of oxygen [7]. The oxide phases can be predicted when the oxygen partial pressure $\left(\mathrm{PO}_{2}\right)$ is given. Fig. 11 shows the calculated $\mathrm{PO}_{2}$ as a function of metal oxide composition in a Fe-Cr-O system at $600{ }^{\circ} \mathrm{C}$ using the FactSageEdu program [46]. At high $\mathrm{PO}_{2}\left(>10^{-10} \mathrm{~atm}\right)$, the stable oxide of corundum $\left(\mathrm{M}_{2} \mathrm{O}_{3}\right)$ will form, which agrees well with the observed $\mathrm{Fe}_{2} \mathrm{O}_{3}$ in the outer oxide of F-M steels in oxygenated SCW [2,11]. As the $\mathrm{PO}_{2}$ drops to a lower level, such as in deaerated $\mathrm{SCW}, \mathrm{M}_{3} \mathrm{O}_{4}$ will form. In the current study, the $\mathrm{PO}_{2}$ in the bulk deaerated water should be at the levels between $10^{-25}-10^{-15}$ atm, thus magnetite $\left(\mathrm{Fe}_{3} \mathrm{O}_{4}\right)$ was formed in the outer oxide layer. Due to the inhibition effect of oxide layers, the $\mathrm{PO}_{2}$ at the oxide-metal interface is very low at the beginning of the test $\left(10^{-32}-10^{-25}\right.$ atm), and an internal oxide layer with spinel precipitates $\left(\mathrm{M}_{3} \mathrm{O}_{4}\right.$, with $\left.\mathrm{M}=\mathrm{Fe}+\mathrm{Cr}\right)$ tends to form. As the exposure time increases, the $\mathrm{PO}_{2}$ in front of the internal oxide layer further drops to $10^{-35}-10^{-32}$ atm due to the diffusion barriers 
of thicker oxide layers, and a continuous $\mathrm{Cr}$-rich spinel oxide layer forms at the matrix-internal oxide layer interface. The internal layer will be further oxidized and transform into an inner layer with $(\mathrm{Fe}, \mathrm{Cr})_{3} \mathrm{O}_{4}$ since the $\mathrm{PO}_{2}$ is higher between outer and internal layers. while $\mathrm{Fe}$, $\mathrm{Cr}$ spinel $\left((\mathrm{Fe}, \mathrm{Cr})_{3} \Theta_{4}\right)$ was formed in the inner oxide layer. As the oxide grows thicker, the $\mathrm{PO}_{2}$ at the metal-oxide interface continues to drop to a lower level $\left(10^{-32}=10^{-25} \mathrm{~atm}\right)$, and tends to form an internal oxide layer with spinel $\left(\mathrm{M}_{3} \mathrm{O}_{4}\right.$, with $\left.\mathrm{M}=\mathrm{Fe}+\mathrm{Cr}\right)$ precipitates. As the exposure time increases, the $\mathrm{PO}_{z}$ in front of the internal oxide layer further dropps to $10^{-35}=10^{-32}$ atm due to the diffusion barriers of thicker oxide layers, and a continuous $C r$ rich spinel oxide layer forms at the matrix internal oxide layer interface. These predicted oxide phases agree well with the observed oxide layers in this study, and are indicated in Fig. 11 for better comparison.

Except for the defective outer oxide layer, all the other oxide layers seem to serve as protective barriers to slow down the inwards diffusion of oxygen. As the diffusivity of oxygen decreases over the depth of surface oxide, the $\mathrm{PO}_{2}$ also decreases, resulting in the formation of different oxide phases. Although the high density defects in the oxide and the grain/lath boundaries are fast diffusion channels for oxygen, they will not change the decreasing $\mathrm{PO}_{2}$ over depth of the oxide. It should be noted that the $\mathrm{PO}_{2}$ only determines the phase of formed oxide, but does not reflect the oxidation rate, nor the transformation process between different oxide layers. The formation and evolution of the oxide layers, especially the internal oxide layer and the continuous Cr-rich oxide layer, are discussed in the following sections.

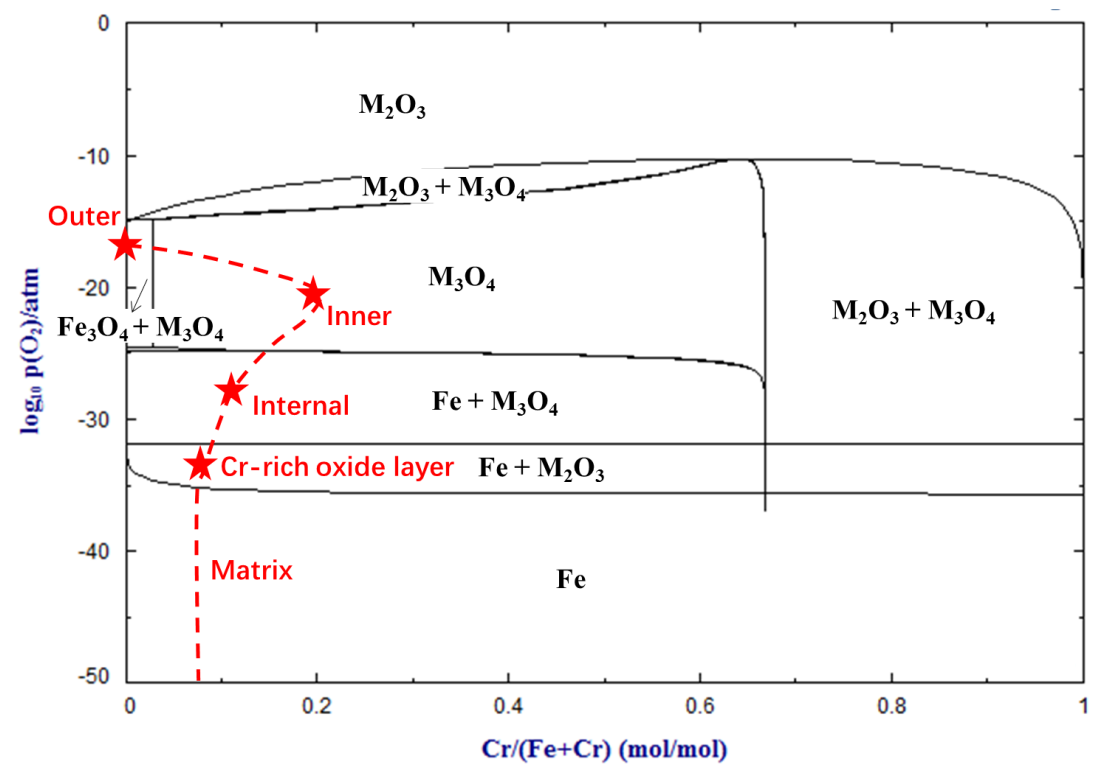

Fig. 11 Calculated oxygen partial pressure versus composition diagram of the $\mathrm{Fe}-\mathrm{Cr}-\mathrm{O}$ ternary system at $600{ }^{\circ} \mathrm{C}$ using the FactSageEdu program [46]. M represents Fe+Cr.

\subsection{Evolution of the internal oxide layer}

In literature, the inner oxide layer has been widely studied, and is mostly described as $\mathrm{Fe}-\mathrm{Cr}$ spinel $\left(\mathrm{Fe}_{3-\mathrm{x}} \mathrm{Cr}_{\mathrm{x}} \mathrm{O}_{4}\right.$ with $\mathrm{x}$ between 0.6 and 0.8) [47-50]. However, the high-resolution EELS results (Fig. 9) confirmed two kinds of oxide with $\mathrm{Fe}-\mathrm{Cr}$ separation, one of which is $\mathrm{Cr}$-rich oxide precipitate. TEM analysis of the inner oxide layer in HCM12A steel after exposed in $600{ }^{\circ} \mathrm{C} \mathrm{SCW}$ for 2 weeks also showed inhomogeneous $\mathrm{Fe}$ and $\mathrm{Cr}$ distributions with nanometric separation of $\mathrm{Cr}$ and $\mathrm{Fe}$ [26]. Thus, attempts to obtain a single $\mathrm{x}$ value in the stoichiometry of $\mathrm{Fe}_{3-\mathrm{x}} \mathrm{Cr}_{\mathrm{x}} \mathrm{O}_{4}$ are meaningless in the inner and internal oxide layers. Since the formation of the inner oxide layer is the result of further oxidation of the internal oxide layer, it is more reasonable to understand the evolution of the internal oxide 
layer in order to explain the formation of Cr-rich oxide precipitates.

Despite the results in this study, TEM results of the internal oxide layer in literatures $[10,26,33]$ also revealed the presence of $\mathrm{Cr}$-rich oxide precipitates for F-M steels. An internal layer containing a mixture of oxide precipitates and metal grains was reported for $\mathrm{HCM} 12 \mathrm{~A}$ steel at $600{ }^{\circ} \mathrm{C}$ [51]. Bischoff [26,33] also observed the nanometric $\mathrm{Cr}-$ rich spinel oxides in the internal oxide layer in $9-12 \% \mathrm{Cr}$ F-M steels. The formation of Cr-rich oxide precipitates along the grain/lath boundaries is expected because the grain/lath boundaries are fast diffusion channels for oxygen where $\mathrm{Cr}$-carbides are present [52]. But the formation of nanometric $\mathrm{Cr}$-rich precipitates inside the grain interior (Figs. 5-7) has not been well explained. Bischoof [26,33] proposed that $\mathrm{Fe}-\mathrm{Cr}$ segregation would occur once the oxygen diffuses into the grain interior in the internal oxide layer due to the negligible solubility of oxygen in $\mathrm{Fe}$, following by the formation of $\mathrm{FeCr}_{2} \mathrm{O}_{4}$ precipitates within the metal. Ye [10] proposed internal oxidation as the feasible explanation, in which the diffusion of oxygen into an alloy caused sub-surface precipitation of Cr-rich oxides in an $\mathrm{Fe}-\mathrm{Cr}$ alloy. An essential condition for the occurrence of internal oxidation is that the $\mathrm{Cr}$ concentration is lower than a critical value below which the outward diffusion of $\mathrm{Cr}$ is lower than the inward diffusion of oxygen to prevent the establishment of an external continuous scale of oxide [10,53]. The explanations by Bischoof [26,33] and Ye [10] are very similar, and are based on the assumption of negligible $\mathrm{Cr}$ diffusion that the inward diffusion of oxygen is faster than the outward diffusion of $\mathrm{Cr}$ in the matrix. This is true at the beginning of the test when the inward diffusion of oxygen is fast due to the thin oxide layers. At this time, the internal oxidation could readily occur at the front of the oxide in the grain interior, and well explains the formation of Cr-rich oxide precipitates. Thus, the development and advancement of internal oxide layer at the early stage are contributed by the oxidation of grain/lath boundaries and the formation of $\mathrm{Cr}$-rich oxide precipitates in the grain interior.

\subsection{Transition from internal to external oxidation}

However, a continuous thin $\mathrm{Cr}$-rich spinel oxide layer formed at the front of the matrix-internal oxide layer interface after $1500 \mathrm{~h}$ exposure, which did not show up after $100 \mathrm{~h}$ exposure. Different from the discrete Cr-rich oxide precipitates formed in the inner and internal oxide layers which are the results of internal oxidation as discussed above, this continuous Cr-rich oxide layer is the obvious evidence of external oxidation. According to the high-temperature oxidation theory [10], the transition from internal to external oxidation would readily occur when the outward diffusion of alloy element exceeds the inward diffusion of oxygen. As the oxide thickness grows with exposure time, both the oxygen concentration and diffusion rate decrease dramatically over the oxide depth due to the impediment effect. In comparison, the nano-scale $\mathrm{Cr}$ diffusion rate in the grain interior remains unchanged due to the constant $\mathrm{Cr}$ concentration. Once the oxygen diffusion rate into the grain interior decreases to a certain value that is lower than the nano-scale diffusion rate of $\mathrm{Cr}$, the internal oxidation would be interrupted, and a continuous Cr-rich oxide would form eventually at the matrix-internal oxide layer interface [10].

The above discussion demonstrated the internal oxidation process at the early stage, and the transition from internal to external oxidation after a long-time exposure. To better understand this phenomenon, the diffusion rate ratio of $\mathrm{O}$ and $\mathrm{Cr}$ over the depth of oxide when a thick oxide is established after a long-time exposure is illustrated in Fig. 12. Due to the high-density defects in the outer oxide layer, the diffusion rate of oxygen $\left(D_{\mathrm{O}}\right)$ is supposed to remain almost unchanged across the outer oxide layer. As the oxygen diffuses into the inner and internal oxide layers, the $D_{\mathrm{O}}$ drops dramatically due to the impediment effect of oxides. When the $D_{\mathrm{O}}$ drops to a critical value below which the inward diffusion of oxygen is slower than the outward diffusion of $\mathrm{Cr}$, the internal oxidation will be interrupted to form a continuous Cr-rich oxide layer at the front of the metal-oxide interface. 


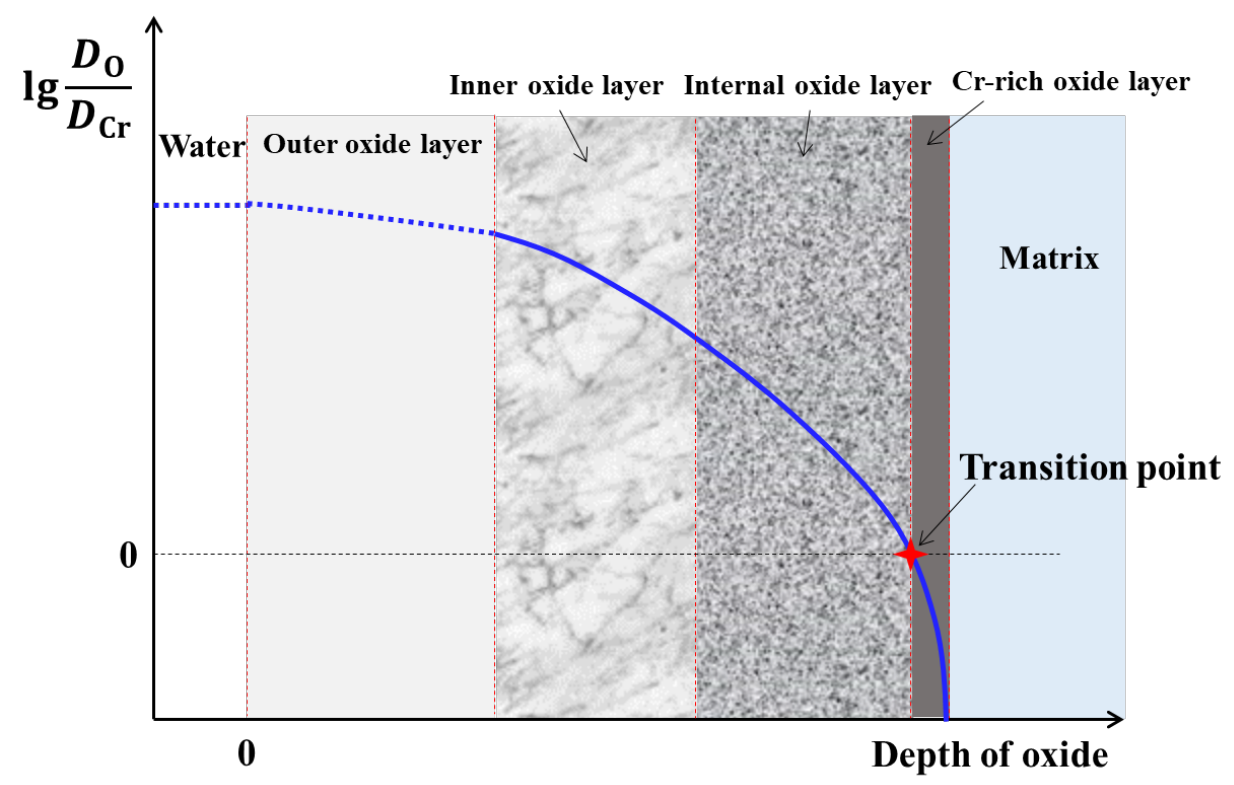

Fig. 12. Illustration of the diffusion rate ratio $(\mathrm{O}$ over $\mathrm{Cr})$ across the depth of a thick oxide showing the transition from internal to external oxidation.

The Cr-rich oxide precipitates in the internal oxide layer have been reported by several studies for F-M steels in supercritical water/steam and in liquid PBE [10,22-30], but the continuous Cr-rich oxide layer at the metal-oxide interface was rarely observed. Part of the reason is that the continuous $\mathrm{Cr}$-rich oxide layer was too thin to be observed by SEM imaging, and most of the literature work did not conducted high-resolution TEM work to reveal the presence of this continuous Cr-rich oxide layer. The other main reason is that this continuous Cr-rich oxide layer would not always form, and only develop under some certain circumstances. Table 2 summarizes the oxidation phenomena for some F-M steels under various conditions. Some studies [26,28,33,54], including the current work, observed the continuous Cr-rich oxide layer at the matrix-internal oxide layer interface for the same alloy only under some certain circumstances. It seems that the occurrence of this continuous Cr-rich oxide layer depends on the testing parameters, oxidation time, and Cr content. Results in Table 2 show that F-M steels with higher Cr content exposed at higher temperature for a longer exposure time with less dissolved oxygen tended to form the continuous Cr-rich oxide layer at the matrix-internal oxide layer interface.

As discussed above, the continuous Cr-rich oxide layer would readily occur when the inward diffusion of oxygen decreases to a certain value that is lower than the outward diffusion of $\mathrm{Cr}$ where the transition from internal to external oxidation occurs. The inward diffusion of oxygen is affected by the oxygen concentration in the bulk environment, the environmental temperature, and the oxide thickness. In the environment with a high oxygen concentration and at a high temperature, the inwards oxygen diffusion will be fast to establish the internal oxidation at the front of the oxide. In comparison, the transition from internal to external oxidation occurs when the inward diffusion of oxygen is slowed down to a very low value at the metal-oxide interface after a long-time exposure. That means the Cr-rich oxide precipitates in the internal oxide layer induced by the internal oxidation will always occur at the early stage of oxidation, while the continuous Cr-rich oxide layer at the oxidation front may form later depending on the testing parameters and oxidation time.

The other method to facilitate the formation of the continuous Cr-rich oxide layer is to increase the Cr content of the alloy. Meier and Jung [54] studied the required Cr content to form a continuous external Cr-rich oxide layer on a simple binary $\mathrm{Fe}-\mathrm{Cr}$ alloy based on experiments and calculations using the classic Wagner model. After 
exposure in $\mathrm{Ar}-20 \% \mathrm{H}_{2} \mathrm{O}$ at $650{ }^{\circ} \mathrm{C}$ for $96 \mathrm{~h}$, a thin $\mathrm{Cr}_{2} \mathrm{O}_{3}$ layer was formed in $\mathrm{Fe}-22 \mathrm{Cr}$ alloy, but not in $\mathrm{Fe}-10 \mathrm{Cr}$ or $\mathrm{Fe}-13 \mathrm{Cr}$ alloys. It was found that the critical $\mathrm{Cr}$ concentration for continuous $\mathrm{Cr}$-rich oxide layer formation in this temperature is $\sim 16 \mathrm{wt} \%$ in water vapor, and $10 \mathrm{wt} \%$ in dry air. However, their work only considered the effect of $\mathrm{Cr}$ content on the outward diffusion of $\mathrm{Cr}$, and ignored the effect of environmental parameters, such as temperature and dissolved oxygen. After all, the formation of the continuous Cr-rich oxide layer at the metal-oxide interface is more complex than the other oxide layers and is affected by various factors, which still needs further investigation.

Table 2 Summary of the oxidation phenomena for F-M alloys under various conditions

\begin{tabular}{|c|c|c|c|c|c|c|}
\hline Alloy & $\begin{array}{c}\mathrm{Cr} \\
\text { content }\end{array}$ & Environment & Temperature & $\begin{array}{l}\text { Oxidation } \\
\text { time }\end{array}$ & $\begin{array}{l}\text { Observation of the } \\
\text { continuous Cr-rich } \\
\text { oxide at the metal- } \\
\text { oxide interface? }\end{array}$ & Ref. \\
\hline T91 & $8.93 \%$ & $\begin{array}{c}\text { Argon } \\
\text { deaerated SCW }\end{array}$ & $600^{\circ} \mathrm{C}$ & $100 \mathrm{~h}$ & No & $\begin{array}{l}\text { This } \\
\text { study }\end{array}$ \\
\hline T91 & $8.93 \%$ & $\begin{array}{c}\text { Argon } \\
\text { deaerated SCW }\end{array}$ & $600^{\circ} \mathrm{C}$ & $1500 \mathrm{~h}$ & Yes & $\begin{array}{l}\text { This } \\
\text { study }\end{array}$ \\
\hline HCM12A & $10.83 \%$ & $\begin{array}{c}\text { SCW with } \\
\text { 10 20 ppb DO }\end{array}$ & $500^{\circ} \mathrm{C}$ & 2-6 weeks & No & [33] \\
\hline HCM12A & $10.83 \%$ & $\begin{array}{c}\text { SCW with } \\
10 \sim 20 \text { ppb DO }\end{array}$ & $600^{\circ} \mathrm{C}$ & 2 weeks & No & [33] \\
\hline HCM12A & $10.83 \%$ & $\begin{array}{c}\text { SCW with } \\
10 \sim 20 \text { ppb DO }\end{array}$ & $600^{\circ} \mathrm{C}$ & 4-6 weeks & Yes & {$[26,33]$} \\
\hline P92 & $8.63 \%$ & deaerated SCW & $560-600^{\circ} \mathrm{C}$ & $400 \mathrm{~h}$ & No & [28] \\
\hline $\mathrm{P} 92$ & $8.63 \%$ & deaerated SCW & $620-650^{\circ} \mathrm{C}$ & $400 \mathrm{~h}$ & Yes & {$[28]$} \\
\hline $\mathrm{Fe}-10 \mathrm{Cr}$ & $10.0 \%$ & $\mathrm{Ar}-20 \% \mathrm{H}_{2} \mathrm{O}$ & $650^{\circ} \mathrm{C}$ & $96 \mathrm{~h}$ & No & [54] \\
\hline $\mathrm{Fe}-13.5 \mathrm{Cr}$ & $13.5 \%$ & Ar- $20 \% \mathrm{H}_{2} \mathrm{O}$ & $650^{\circ} \mathrm{C}$ & $96 \mathrm{~h}$ & No & [54] \\
\hline $\mathrm{Fe}-22 \mathrm{Cr}$ & $22.0 \%$ & Ar- $20 \% \mathrm{H}_{2} \mathrm{O}$ & $650^{\circ} \mathrm{C}$ & $96 \mathrm{~h}$ & Yes & {$[54]$} \\
\hline
\end{tabular}

\subsection{Regulation of the oxidation rate}

The surface oxide of T91 shows a triplex structure, and not all the oxide layers have protective effect to determine/control the oxidation rate. The outer oxide layer shows high density of defects with almost no protective effect for the ion diffusion. The inner and internal oxide layers are denser to slow down the diffusion of $\mathrm{Fe}$ and oxidant. The main difference between the inner and internal oxide layers is that the un-oxidized matrix in the internal oxide layer is further oxidized into Fe-rich oxide in the inner oxide layer (Fig. 9). Although part of the internal oxide layer develops into inner oxide layer over time, the thickness of the internal oxide layer is still growing with increasing exposure time (Fig. 3d), which means that the formation rate of the internal oxide layer is faster than the inner oxide layer. Thus, we believe that the formation rate of the internal oxide layer reflects the overall oxide growth rate of the whole surface oxide scale.

There are debates on the controlling factor of the oxidation rate for F-M steels. According to the "available space model" [18-21], the outward diffusion of Fe determines the oxidation rate, while other researchers [7] believed that the inward diffusion of oxygen along short circuit paths, such as grain/lath boundaries and defects, controls the oxidation rate. Whether the diffusion of $\mathrm{Fe}$ or oxygen controls the oxidation rate, the concentration gradients of $\mathrm{Fe}$ and oxygen are only observed in the internal oxide layer, while they remain constant in the inner and outer oxide 
layers, as shown in Fig. 3a-c. That means the diffusion of Fe and oxygen are slowed down dramatically in the internal oxide layer due to the block effect. As a result, the growth of the internal oxide layer regulates the overall oxidation rate of the whole surface oxide. Additionally, a continuous Cr-rich oxide layer at the front of the oxide will readily form when the oxide is thick enough under some circumstances. It is well known that the Cr-rich oxide has better protective effect than Fe-rich oxide because $\mathrm{Cr}$ is much more stable in the octahedral sites than $\mathrm{Fe}$ [33], and this would further decrease the diffusivity of $\mathrm{Fe}$ and oxygen through oxides [54], thus slowing down the oxidation rate. The formation of this continuous $\mathrm{Cr}$-rich oxide layer after $1500 \mathrm{~h}$ exposure certainly slows down the overall oxidation rate, and could also be part of the reason for the lower time exponents (Fig. 3d) deviated from the theoretical parabolic law. In this way, it is recommended to increase the $\mathrm{Cr}$ content and decrease the oxygen concentration in the bulk environment to facilitate the formation of a continuous $\mathrm{Cr}$-rich oxide layer at the oxidation front, thus increasing the oxidation resistance.

However, above discussion is based on the formation of a uniform and stable surface oxide without exfoliation. In some cases, the oxide film would spall when it is thick enough, and lead to severe localized oxidation regardless of the formation of protective oxide layers. Zhang [55] studied the effect of dissolved oxygen (100-2000 ppb) on the corrosion behavior of $\mathrm{P} 92$ steel in $550^{\circ} \mathrm{C} \mathrm{SCW}$, and found that high dissolved oxygen content tended to facilitate the formation of cracks and exfoliation of oxide scale, which might be attributed to the formation of a volatile phase $\mathrm{CrO}_{3}$ or $\mathrm{CrO}_{2}(\mathrm{OH})_{2}$ at oxide-metal interface. Meier and Jung [54] reported that excess oxygen could greatly increase the oxidation rate of $\mathrm{Fe}-22 \mathrm{Cr}$ alloy by accelerating reactive evaporation of the protective $\mathrm{Cr}$-rich oxides. However, exfoliation never occurred when the continuous Cr-rich oxide layer was formed in this study and in literature $[26,28,33,54]$. This is because the continuous Cr-rich oxide is more compact and protective to greatly slow down the diffusion of oxygen, thus inhibit further oxidation into the base metal. As a result, the formation of volatile $\mathrm{Cr}$ phases decreases remarkably. While in oxygenated water at high temperature, the oxygen diffusion into the oxide is fast and could easily over-oxidize $\mathrm{Cr}$ at the oxide-metal interface to facilitate the formation of volatile $\mathrm{Cr}$ phases, which contributes to the exfoliation of oxides.

\section{Conclusions}

The surface oxide films of T91 F-M steel after exposure to deaerated SCW at $600{ }^{\circ} \mathrm{C}$ for $100-1500 \mathrm{~h}$ were characterized in detail through SEM, TEM, and TKD. The results and discussion lead to the following conclusions concerning the oxide evolution over time.

(1) A triplex oxide scale is formed on T91, consisting of an outer $\mathrm{Fe}_{3} \mathrm{O}_{4}$ oxide layer, an inner $(\mathrm{Fe}, \mathrm{Cr})_{3} \mathrm{O}_{4}$ spinel layer and an internal oxide layer. Each oxide layer grows simultaneously-keeps growing with increasing exposure time, and follows a growth behavior in between parabolic and cubic laws with the exponent of 0.35 0.48 .

(2) Cr-rich oxide precipitates along the grain/lath boundaries as well as in the grain interior are observed in the internal oxide layer. The former ones are the result of preferential oxidation along the grain/lath boundaries, while the later ones are the result of internal oxidation.

(3) The inner oxide layer consists of Cr-rich spinel oxide precipitates surrounded by Fe-rich spinel oxide. The formation of the inner oxide layer is the result of further oxidation of the internal oxide layer where the metal matrix in the grain interior is oxidized into Fe-rich spinel.

(4) A continuous thin Cr-rich spinel oxide layer is observed at the oxidation front after $1500 \mathrm{~h}$ exposure, but did not show up after $100 \mathrm{~h}$ exposure. The formation of this $\mathrm{Cr}$-rich layer is believed to be the result of the transition from internal to external oxidation, where the nano-scale outward diffusion rate of $\mathrm{Cr}$ exceeds the inward diffusion of oxygen when the oxide is thick enough to dramatically slow down the inward diffusion of oxygen. 


\section{Acknowledgement}

This work was supported by the National Key Research and Development Program of China [YS2018YFE010246, 2017YFB0702203], and EPSRC [EP/K040375/1, EP/N010868/1, EP/R009392/1]. Prof. Sergio Lozano-Perez are acknowledged for useful discussion.

\section{Reference}

[1] X.J. Liu, M.Q. Song, X. Cheng, Current status and challenges of supercritical fluid thermal hydraulics, Nucl. Eng. Des. 354 (2019) 110176.

[2] G.S. Was, P. Ampornrat, G. Gupta, S. Teysseyre, E.A. West, T.R. Allen, K. Sridharan, L. Tan, Y. Chen, X. Ren, C. Pister, Corrosion and stress corrosion cracking in supercritical water, J. Nucl. Mater. 371 (2007) 176-201.

[3] X.J. Liu, X. Cheng, Thermal-hydraulic and neutron-physical characteristics of a new SCWR fuel assembly, Ann. Nucl. Energy 36 (1) (2009) 28-36.

[4] W. Zhang, D. Guzonas, K.P. Boyle, J. Li, S. Xu, Materials assessment for the Canadian SCWR core concept, JOM 68 (2) (2016) 456-462.

[5] L. Zhang, Y. Bao, R. Tang, Selection and corrosion evaluation tests of candidate SCWR fuel cladding materials, Nucl. Eng. Des. 249 (2012) 180-187.

[6] M. Song, C. Sun, Z. Fan, Y. Chen, R. Zhu, K.Y. Yu, K.T. Hartwig, H. Wang, X. Zhang, A roadmap for tailoring the strength and ductility of ferritic/martensitic T91 steel via thermo-mechanical treatment, Acta Mater. 112 (2016) 361-377.

[7] P. Ampornrat, G.S. Was, Oxidation of ferritic-martensitic alloys T91, HCM12A and HT-9 in supercritical water, J. Nucl. Mater. 371 (2007) 1-17.

[8] C. Sun, R. Hui, W. Qu, S. Yick, Progress in corrosion resistant materials for supercritical water reactors, Corros. Sci. 51 (2009) 2508-2523.

[9] G.S. Was, T.R. Allen, Chapter 6 - Corrosion issues in current and next-generation nuclear reactors, Editor(s): G.R. Odette, S.J. Zinkle, Structural Alloys for Nuclear Energy Applications, Elsevier, 2019, Pages 211-246.

[10] Z. Ye, P. Wang, H. Dong, D. Li, Y. Zhang, Y. Li, Oxidation mechanism of T91 steel in liquid lead-bismuth eutectic: with consideration of internal oxidation. Sci. Rep. 6 (2019) 35268.

[11] L. Martinelli, C. Desgranges, F. Rouillard, K. Ginestar, M. Tabarant, K. Rousseau, Comparative oxidation behaviour of $\mathrm{Fe}-9 \mathrm{Cr}$ steel in $\mathrm{CO} 2$ and $\mathrm{H} 2 \mathrm{O}$ at $550^{\circ} \mathrm{C}$ : Detailed analysis of the inner oxide layer, Corros. Sci. 100 (2015) 253-266.

[12] L. Martinelli, F. Balbaud-Célérier, A. Terlain, S. Bosonnet, G. Picard, G. Santarini, Oxidation mechanism of an Fe-9Cr-1 Mo steel by liquid Pb-Bi eutectic alloy at $470{ }^{\circ} \mathrm{C}$ (Part II), Corros. Sci. 50 (2008) 2523-2536.

[13] I.G. Wright, R.B. Dooley, A review of the oxidation behaviour of structural alloys in steam, Int. Mater. Rev. 55 (3) (2010) 129-167.

[14] M. Montgomery, S.A. Jensen, F. Rasmussen, T. Vilhelmsen, Fireside corrosion and steamside oxidation of 9$12 \% \mathrm{Cr}$ martensitic steels exposed for long term testing, Corros. Eng., Sci. Technol. 44 (3) (2009) 196-210.

[15] Atkinson, R.I. Taylor, 55Fe and $18 \mathrm{O}$ tracers in magnetite scales growing on iron and dilute iron-silicon alloys, High Temp. High Pressures 14 (1982) 571.

[16] M.R. Taylor, J.M. Calvert, D.G. Lees, D.B. Meadowcroft, The mechanism of corrosion of Fe-9\%Cr alloys in carbon dioxide, Oxid. Met. 14 (6) (1980) 499-516.

[17] A.M. Pritchard, N.E.W. Hartley, J.F. Singleton, A.E. Truswell, Oxygen-18 and deuterium profiling in thick films on Fe-9\% Cr alloys by $3 \mathrm{MeV}$ nuclear microprobe, Corros. Sci. 20 (1980) 1-17.

[18] Brückman, J. Romanski, On the mechanism of sulphide scale formation on iron, Corros. Sci. 5 (1965) 185190.

[19] G.B. Gibbs, R. Hales, The influence of metal lattice vacancies on the oxidation of high temperature materials, Corros. Sci. 17 (1977) 487-507.

[20] R. Hales, A.C. Hill, The role of metal lattice vacancies in the high temperature oxidation of nickel, Corros. Sci. 12 (1972) 843-853. 
[21] J. Robertson, The mechanism of high temperature aqueous corrosion of steel, Corros. Sci. 29 (1989) 12751291.

[22] N. Zhang, Z. Zhu, H. Xu, X. Mao, J. Li, Oxidation of ferritic and ferritic-martensitic steels in flowing and static supercritical water, Corros. Sci. 103 (2016) 124-131.

[23] L. Tan, X. Ren, T.R. Allen, Corrosion behavior of 9-12\% Cr ferritic-martensitic steels in supercritical water, Corros. Sci. 52 (2010) 1520-1528.

[24] X. Zhong, X. Wu, E. Han, The characteristic of oxide scales on T91 tube after long-term service in an ultrasupercritical coal power plant, J. Supercrit. Fluids 72 (2012) 68-77.

[25] Y. Li, S. Wang, P. Sun, J. Yang, X. Tang, D. X, Y. Guo, J. Yang, D.D., Macdonald, Investigation on early formation and evolution of oxide scales on ferritic-martensitic steels in supercritical water, Corros. Sci. 135 (2018) 136-146.

[26] J. Bischoff, A.T. Motta, EFTEM and EELS analysis of the oxide layer formed on HCM12A exposed to SCW, J. Nucl. Mater. 430 (2012) 171-180.

[27] Y. Yang, Q. Yan, Y. Yang, L. Zhang, C. Ge, Corrosion behavior of ferritic/martensitic steels CNS- I and modified CNS- II in supercritical water, J. Iron Steel Res. 19 (5) (2012) 69 - 73.

[28] Z. Zhu, H. Xu, D. Jiang, X. Mao, N. Zhang, Influence of temperature on the oxidation behavior of a ferriticmartensitic steel in supercritical water, Corros. Sci. 113 (2016) 172-179.

[29] X. Zhong, X. Wu, E. Han, Effects of exposure temperature and time on corrosion behavior of a ferriticmartensitic steel P92 in aerated supercritical water, Corros. Sci. 90 (2015) 511-521.

[30] D. Gómez-Briceño, F. Blázquez, A. Sáez-Maderuelo, Oxidation of austenitic and ferritic/martensitic alloys in supercritical water, J. Supercrit. Fluids 78 (2013) 103-113.

[31] S. Fetni, A. Toumi, I. Mkaouar, C. Boubahri, J. Briki, Microstructure evolution and corrosion behaviour of an ASTM A213 T91 tube after long term creep exposure, Eng. Failure Anal. 79 (2017) 575-591.

[32] J. Bischoff, A.T. Motta, C. Eichfeld, R.J. Comstock, G. Cao, T.R. Allen, Corrosion of ferritic-martensitic steels in steam and supercritical water, J. Nucl. Mater. 441 (2013) 604-611.

[33] J. Bischoff, A.T. Motta, Oxidation behavior of ferritic-martensitic and ODS steels in supercritical water, J. Nucl. Mater. 424 (2012) 261-276.

[34] J. Zurek, E. Wessel, L. Niewolak, F. Schmitz, T.-U. Kern, L. Singheiser, W.J. Quadakkers, Anomalous temperature dependence of oxidation kinetics during steam oxidation of ferritic steels in the temperature range 550-650 C, Corros. Sci. 46 (2004) 2301-2317.

[35] Y. Chen, K. Sridharan, S. Ukai, T.R. Allen, Oxidation of 9Cr oxide dispersion strengthened steel exposed in supercritical water, J. Nucl. Mater. 371 (2007) 118-128.

[36] X. Guo, Y. Fan, W. Gao, R. Tang, K. Chen, Z. Shen, L. Zhang, Corrosion resistance of candidate cladding materials for supercritical water reactor, Ann. Nucl. Energy 127 (2019) 351-363.

[37] Z. Shen, K. Chen, X. Guo, L. Zhang, A study on the corrosion and stress corrosion cracking susceptibility of 310-ODS steel in supercritical water, J. Nucl. Mater. 514 (2019) 56-65.

[38] X. Guo, K. Chen, W. Gao, Z. Shen, P. Lai, L. Zhang, A research on the corrosion and stress corrosion cracking susceptibility of 316L stainless steel exposed to supercritical water, Corros. Sci. 127 (2017) 157-167.

[39] X. Guo, W. Gao, K. Chen, Z. Shen, L. Zhang, Corrosion and stress corrosion cracking susceptibility of type 347H stainless steel in supercritical water, Corrosion 74 (2018) 83-95.

[40] K. Chen, J. Wang, D. Du, X. Guo, L. Zhang, P.L. Andresen, Stress corrosion crack growth behavior of type 310S stainless steel in supercritical water, Corrosion 74 (2018) 776-787.

[41] X. Guo, K. Chen, W. Gao, Z. Shen, L. Zhang, Corrosion behavior of alumina-forming and oxide dispersion strengthened austenitic 316 stainless steel in supercritical water, Corros. Sci. 138 (2018) 297-306.

[42] Y. Chen, K. Sridharan, T. Allen, Corrosion behavior of ferritic-martensitic steel T91 in supercritical water, Corros. Sci. 48 (2006) 2843-2854.

[43] A.S. Khanna, High Temperature Oxidation and Corrosion, ASM International, 2002, p. 20-37.

[44] D. Gupta, A.D. Romig, M.A. Dayananda, Diffusion processes in high technology materials, in: Proceedings of the ASM symposium, Trans tech publications Ltd., Switzerland, 1988, p. 1.

[45] B. Bokstein, N. Balandina, Grain boundary diffusion and grain boundary segregation, in: Proceedings of the International Workshop DiBoS-97, Scitec Publications Ltd., 1998. 
[46] C.W. Bale, E. Bélisle, P. Chartrand, S.A. Decterov, G. Eriksson, A.E. Gheribi, K. Hack, I.H. Jung, Y.B. Kang, J. Melançon, A.D. Pelton, S. Petersen, C. Robelin, J. Sangster, M-A. Van Ende, FactSage Thermochemical Software and Databases, 2010-2016, CALPHAD 54 (2016) 35-53. <www.factsage.com>.

[47] F. Rouillard, G. Moine, L. Martinelli, J.C. Ruiz, Corrosion of 9Cr steel in CO2 at intermediate temperature I: mechanism of void-induced duplex oxide formation, Oxid. Met. 77 (2012) 27-55.

[48] T. Jonsson, B. Pujilaksono, H. Heidari, F. Liu, J.E. Svensson, M. Halvarsson, L.G. Johansson, Oxidation of $\mathrm{Fe}-10 \mathrm{Cr}$ in $\mathrm{O} 2$ and in $\mathrm{O} 2+\mathrm{H} 2 \mathrm{O}$ environment at $600^{\circ} \mathrm{C}$ : A microstructural investigation, Corros. Sci. 75 (2013) 326-336.

[49] L. Martinelli, T. Dufrenoy, K. Jaakou, A. Rusanov, F. Balbaud-Célérier, High temperature oxidation of Fe$9 \mathrm{Cr}-1 \mathrm{Mo}$ steel in stagnant liquid lead-bismuth at several temperatures and for different lead contents in the liquid alloy, J. Nucl. Mater. 376 (2008) 282-288.

[50] L. Martinelli, F. Balbaud-Célérier, Modelling of the oxide scale formation on Fe-Cr steel during exposure in liquid lead-bismuth eutectic in the $450-600{ }^{\circ} \mathrm{C}$ temperature range, Mater. Corros. 62 (6) (2011) 531-542.

[51] L. Tan, M.T. Machut, K. Sridharan, T.R. Allen, Corrosion behavior of a ferritic/martensitic steel HCM12A exposed to harsh environments, J. Nucl. Mater. 371 (2007) 161-170.

[52] J. Bischoff, A.T. Motta, L. Tan, T.R. Allen, Influence of alloy microstructure on oxide growth in HCM12A in supercritical water, in: Materials for Future Fusion and Fission Technologies, 2-4 December 2008, vol. 1125, USA, Materials Research Society, Warrendale, PA, 2009. pp. 19-24.

[53] W. Zhao, Y. Kang, Quantitative approach for determining the critical volume fraction for the transition from internal to external oxidation, Oxid. Met. 83 (2015) 187-201.

[54] G.H. Meier, K. Jung, N. Mu, N.M. Yanar, F.S. Pettit, J.P. Abellán, T. Olszewski, L.N. Hierro, W.J. Quadakkers, G.R. Holcomb, Effect of alloy composition and exposure conditions on the selective oxidation behavior of ferritic Fe-Cr and Fe-Cr-X alloys, Oxid. Met. 74 (2010) 319-340.

[55] N. Zhang, H. Xu, B. Li, Y. Bai, D. Liu, Influence of the dissolved oxygen content on corrosion of the ferriticmartensitic steel P92 in supercritical water, Corros. Sci. 56 (2012) 123-128. 